\title{
Connexin Hemichannels in Astrocytes: Role in CNS Disorders
}

\author{
LingYan Xing ${ }^{1 t}$, Tuo Yang ${ }^{2 t}$, ShuSen Cui ${ }^{2 *}$ and Gang Chen ${ }^{1,3 *}$ \\ ${ }^{1}$ Key Laboratory of Neuroregeneration of Jiangsu and Ministry of Education, Co-innovation Center of Neuroregeneration, \\ Nantong University, Nantong, China, ${ }^{2}$ Department of Hand Surgery, China-Japan Union Hospital of Jilin University, \\ Changchun, China, ${ }^{3}$ Department of Anesthesiology, Affiliated Hospital of Nantong University, Nantong, China
}

In the central nervous system (CNS), astrocytes form networks interconnected by gap junctions made from connexins of the subtypes Cx30 and Cx43. When unopposed by an adjoining hemichannel, astrocytic connexins can act as hemichannels to control the release of small molecules such as ATP and glutamate into the extracellular space. Accruing evidence indicates that astrocytic connexins are crucial for the coordination and maintenance of physiologic CNS activity. Here we provide an update on the role of astrocytic connexins in neurodegenerative disorders, glioma, and ischemia. In addition, we address the regulation of $\mathrm{C} \times 43$ in chronic pain.

\section{OPEN ACCESS}

Keywords: astrocyte, connexin 43, Alzheimer's disease, glioma, ischemia, neuropathic pain

Edited by:

Michele Papa,

Università degli Studi della Campania Luigi Vanvitelli Caserta, Italy

Reviewed by:

Fabrizio Michetti, Catholic University of Sacred Heart,

Italy

Won-Suk Chung, Korea Advanced Institute of Science \& Technology (KAIST), South Korea

*Correspondence:

ShuSen Cui

cuiss@jlu.edu.cn

Gang Chen

chengang6626@ntu.edu.cn

tThese authors have contributed equally to this work

Received: 24 October 2018 Accepted: 21 January 2019 Published: 06 February 2019

Citation:

Xing L, Yang T, Cui S and Chen $G$ (2019) Connexin Hemichannels in Astrocytes: Role in CNS Disorders.

Front. Mol. Neurosci. 12:23. doi: 10.3389/fnmol.2019.00023

\section{INTRODUCTION}

As the most abundant cells in the central nervous system, astrocytes are critical for synaptic transmission and homeostasis maintenance. Astrocyte dysfunction has been associated with many neurological disorders, including but not limited to neurodegenerative diseases, gliomas, and ischemia (Verkhratsky et al., 2010; Yang et al., 2013; Hirayama and Koizumi, 2018). Over the last two decades, accumulating evidence has shown that astrocytes are also key mediators in pain development and maintenance (Ji et al., 2013).

Astrocytes in the CNS form a highly interconnected network via gap junctions or hemichannels. Each connexin hemichannel consists of six protein subunits termed connexins, which belong to a protein family encoded by 20-21 genes in mammals (Scott et al., 2012). An individual subunit possesses four alpha-helical transmembrane domains, connected by two extracellular loops and one intracellular loop, with cytoplasmic carboxyl and amine terminals (Bennett et al., 2016). When one hemichannel docks to its counterpart on the apposed cells, a gap junction is formed. Gap junctions of astrocytes allow rapid intercellular exchange of ions and metabolites, which is critical for $\mathrm{K}^{+}$ and glutamate buffering, calcium wave propagation, and synaptic plasticity (Li et al., 2014; Lapato and Tiwari-Woodruff, 2018). Unpaired connexins can act as hemichannels, which are responsible for the release of gliotransmitters, including ATP, glutamate, nicotinamide adenine dinucleotide (NAD), and D-serine to the extracellular milieu (Saez et al., 2003; Retamal et al., 2014). This offers a new exchange route between neurons and glia.

Accruing evidence suggests that connexin hemichannels can open at both physiological and pathological conditions (Saez et al., 2003). The opening of hemichannels is highly dynamic and can be controlled by multiple regulators. Lower or higher intercellular $\mathrm{Ca}^{2+}$ can increase the opening probability of hemichannels (Decrock et al., 2011). In addition, pathological conditions, such as oxidative stress, lower $\mathrm{pH}$, mechanical stimulation, and inflammation can significantly enhance the hemichannel opening (Johansen et al., 2011; Batra et al., 2014; Castellano and Eugenin, 2014; 
Retamal et al., 2015). The uncontrolled opening of hemichannels can lead to cell damage and homeostatic imbalance (Orellana, 2016). It is accepted that excessive release of ATP and glutamate or overload of intracellular free $\mathrm{Ca}^{2+}$ are toxic to neighboring cells or trigger secondary damages to distant cells (Takeuchi et al., 2006; Orellana et al., 2011). Of note, dysregulation of hemichannels permeability can also induce excessive influx of $\mathrm{Na}^{+}$and $\mathrm{Cl}^{-}$, leading to osmotic and ionic imbalance (Orellana et al., 2016). In astrocytes, the predominant connexins are connexin 43 (Cx43), though $\mathrm{Cx} 26$ and $\mathrm{Cx} 30$ are also detectable (Rash et al., 2001a,b). This review will focus on the role of astrocytic $\mathrm{Cx} 43$ in the regulation of CNS disorders (Table 1, Figure 1). Furthermore, we also discuss an emerging role of astrocyte $\mathrm{Cx} 43$ in chronic pain (Table 2).

\section{CX43 IN NEURODEGENERATIVE DISEASES}

Alzheimer's disease (AD), a representative CNS neurodegenerative disease characterized by plaques and tangles in the brain (Ballard et al., 2011), is the leading cause of dementia worldwide. Until recently, the role of astrocytes in $\mathrm{AD}$ has been appreciated, though astrocytic modification was discovered in AD decades ago (Nagy et al., 1996; Rodríguez et al., 2009; Verkhratsky et al., 2010). Astrogliosis and $\beta$-amyloid(A $\beta$ ) plaque, two prominent pathologic features of $\mathrm{AD}$, are both highly associated with astrocytic connexins, which offer a novel pathological mechanism and a potential therapeutic target for $\mathrm{AD}$ (Yi et al., 2017b). Altered expression of astrocytic connexins have been observed in the brains of both $\mathrm{AD}$ patients and mice (Nagy et al., 1996; Mei et al., 2010), though the mechanisms by which connexins expression is changed, remain controversial. For example, the expression of $\mathrm{Cx} 43$ in astrocytic gap junctions of $\mathrm{AD}$ patients is upregulated in the cortical regions with $\mathrm{A} \beta$ plaques, and some plaques corresponded exactly to the potentiated Cx43 immunoreactive sites (Nagy et al., 1996). In older APP/PS1 mice, a murine model of familial AD, an increase of $\mathrm{Cx} 43$ and $\mathrm{Cx} 30$ immunoreactivity was found in $60-70 \%$ $\mathrm{A} \beta$ plaques of reactive astrocytes. However, a decrease in the expression of $\mathrm{Cx} 43$ and $\mathrm{Cx} 30$ was also found in a few newly formed plaques $(<10 \%)$ (Mei et al., 2010). This discrepancy indicates that the alteration of $\mathrm{Cx} 43$ expression in $\mathrm{AD}$ depends on the amyloid pathology and local inflammatory status of the plaque sites (Koulakoff et al., 2012). The increase in Cx43 expression promotes astroglial activation and further alters astroglial channel function and the pathologic process of AD.

Studies have been performed to investigate the role of $\mathrm{Cx} 43$ in $\mathrm{AD}$, either as gap junction channels or hemichannels. Interestingly, the reactive astrogliosis does not affect astroglial gap junctional communication in APP/PS1 mice (Yi et al., 2017b). Hemichannels in astrocytes, however, can be activated during the pathologic process of $\mathrm{AD}$ and are critical for the neuronal damage (Orellana et al., 2011). The activated hemichannels increase the release of ATP and glutamate from astrocytes around the amyloid plaques, leading to overload of neuronal $\mathrm{Ca}^{2+}$, synaptic depression (Pascual, 2005), and final neuronal damage (Yi et al., 2016). Neuronal damages in the process could be alleviated by $\mathrm{Cx} 43$ hemichannel blocker boldine or cannabinoids (Gajardo-Gómez et al., 2017; Yi et al., 2017a). In addition, in APP/PS1 mice, a specific deletion of astroglial Cx43 could significantly reduce astrogliosis and increase synapse numbers, though it had no effects on amyloid plaque formation or inflammatory response (Ren et al., 2018). These results indicate that $\mathrm{Cx} 43$ could be a novel therapeutic target for AD.

As the second most common chronic neurodegenerative disorder in the CNS, Parkinson's disease (PD) possesses reactive astrocytes in the substantia nigra (Fernandez, 2012; Cabezas et al., 2014). Rotenone is a common neurotoxic substance used for generating PD experimental models. In both rotenonetreated rats and in vitro astrocytes, levels of both total $\mathrm{Cx} 43$ and phosphorylated Cx43 were elevated (Wang Y. et al., 2013). Additionally, gastrodin from a Chinese herbal medicine can ameliorate PD by downregulating Cx43 (Wang Y. et al., 2013). Cx43 expression was also found upregulated in patients with amyotrophic lateral sclerosis (ALS) or related models (Almad et al., 2016). This upregulated $\mathrm{Cx} 43$ expression led to elevated hemichannel activity, enhanced gap junction coupling and increased intracellular $\mathrm{Ca}^{2+}$ concentration, which contributed to motor neuron toxicity. Furthermore, it was conferred that $\mathrm{Cx} 43$ blocker or $\mathrm{Cx} 43$ hemichannel blocker provided protection against this neuron toxicity (Almad et al., 2016).

Overall, the role of astrocytes as well as astrocytic connexins has attracted more attention in the field of neurodegenerative diseases in recent years, due to their critical role in gliosis, inflammation, and neuronal damage (Freitas-Andrade and Naus, 2016). Here we pose several questions and perspectives for further study. First, in-depth studies may be needed to apply and clarify the targets of these interventions, for example, R76W mutant which specifically block gap junction channels (Xu et al., 2015), Gap19 (a specific Cx43 hemichannel blocker) (Wang N. et al., 2013) and non-selective peptides. Second, the discrepancy of Cx43 immunoreactivity in neurodegenerative diseases was found in a previous study (Mei et al., 2010), which may lead us to test how $\mathrm{Cx} 43$ works in a time-dependent manner.

\section{Cx43 IN GLIOMA}

Glioblastoma (GBM), a representative type of malignant glioma, is the most common and aggressive CNS malignant tumor (Sontheimer, 2015). Both the expression changes of $\mathrm{Cx} 43$ and its role in glioma progression are controversial, which may be attribute to high heterogeneity of this tumor (Sin et al., 2012). The expression of $\mathrm{Cx} 43$ varies with grades, stages, and locations of tumors. For example, Cx43 generally exhibits a lower expression in the tumor core within high-grade gliomas compared with low-grade ones (Sin et al., 2016). As a conventional therapeutic strategy, surgical resection supplemented with chemotherapy and radiotherapy confers a poor prognosis in patients with gliomas (Stupp et al., 2005). This poor prognosis is mainly caused by the resistance to the chemotherapeutic alkylating agents such as temozolomide (TMZ), and the invasive nature of the tumor cells (Sin et al., 2012, 2016; Wang et al., 2018). 
TABLE 1 | CX43 in the regulation of CNS disorders.

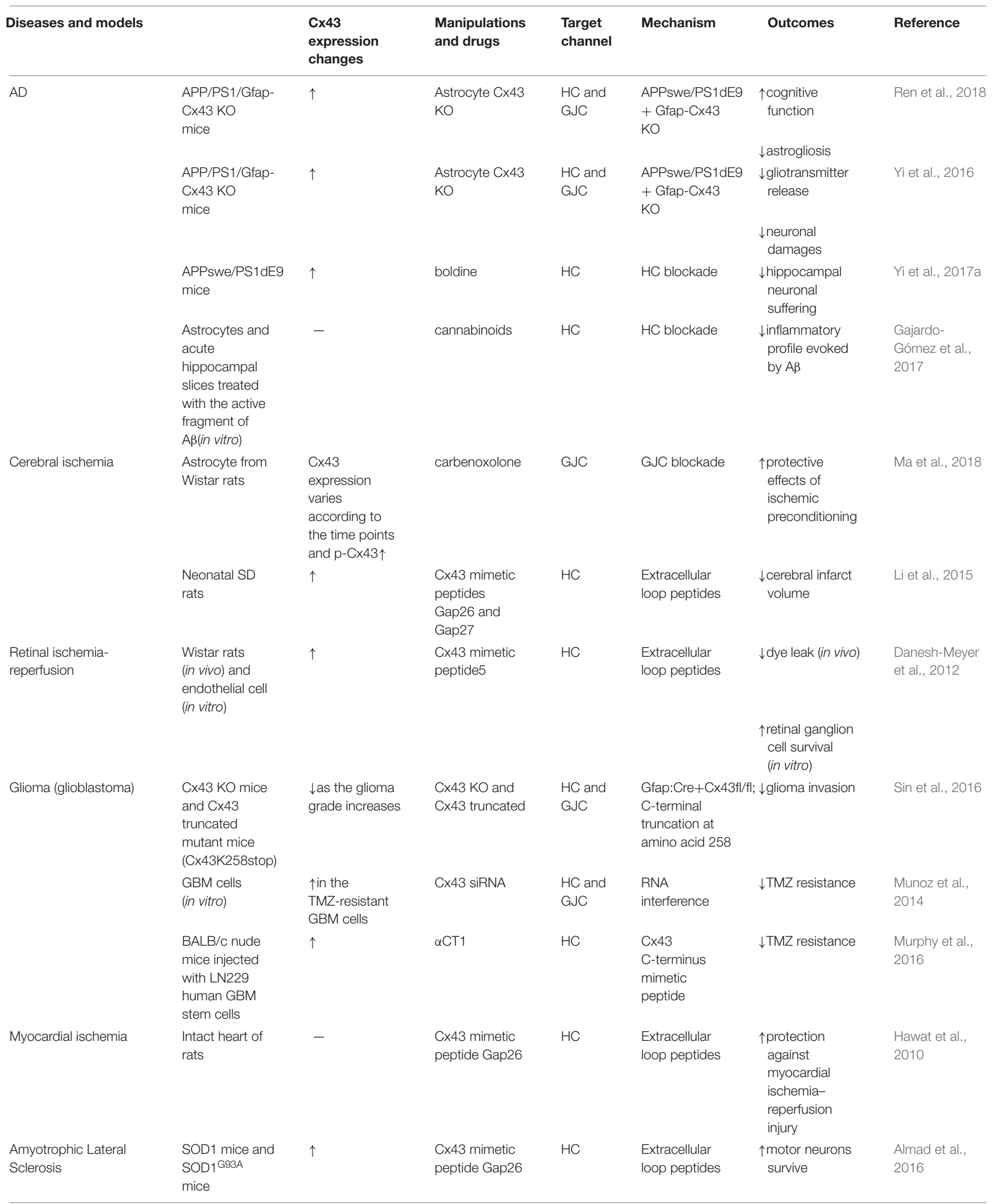

$\uparrow$ denotes upregulation; $\downarrow$ denotes downregulation; - denotes data unavailable. 
TABLE 2 | Expression changes of Cx43 in different pain models.

\begin{tabular}{|c|c|c|c|c|c|c|}
\hline $\begin{array}{l}\text { Pain models and } \\
\text { species }\end{array}$ & $\begin{array}{l}\text { Cx43 expression } \\
\text { changes }\end{array}$ & $\begin{array}{l}\text { Manipulations } \\
\text { and drugs }\end{array}$ & Target channel & Mechanism & Effects on pain & Reference \\
\hline $\begin{array}{l}\text { Spinal cord injury, } \\
\text { mouse }\end{array}$ & $\uparrow$ & $\begin{array}{l}\mathrm{C} \times 43^{-/-} \mathrm{C} \times 30^{-/-} \\
\text {double knockout }\end{array}$ & $\mathrm{HC}$ and GJC & $\begin{array}{l}\mathrm{C} \times 30-\mathrm{KO}+ \\
\text { Gfap:Cre Cx43 }\end{array}$ & $\begin{array}{l}\downarrow \text { heat hyperalgesia } \\
\text { and mechanical } \\
\text { allodynia }\end{array}$ & Chen et al., 2012 \\
\hline $\begin{array}{l}\text { Spinal cord injury } \\
\text { (thoracic spinal cord } \\
\text { hemisection), mouse }\end{array}$ & $\uparrow$ & $\begin{array}{l}\text { Intrathecal injection } \\
\text { of fluorocitrate and } \\
\text { carbenoxolone and } \\
\text { Gap26 }\end{array}$ & $\mathrm{HC}$ and $\mathrm{GJC}$ & $\begin{array}{l}\text { astrocyte metabolic } \\
\text { inhibitor;gap } \\
\text { junction/hemichannel } \\
\text { blocker; Cx43 } \\
\text { extracellular loop } \\
\text { peptides }\end{array}$ & $\begin{array}{l}\downarrow S C l \text {-induced } \\
\text { bilateral below-level } \\
\text { mechanical } \\
\text { allodynia }\end{array}$ & Choi et al., 2016 \\
\hline $\begin{array}{l}\text { Spinal cord contusion, } \\
\text { rat }\end{array}$ & $\uparrow$ & $\begin{array}{l}\text { Intraperitoneal } \\
\text { injection of } \\
\text { Peptide5 }\end{array}$ & $\mathrm{HC}$ & $\begin{array}{l}\text { Cx43 extracellular } \\
\text { loop peptides }\end{array}$ & $\begin{array}{l}\downarrow \text { at-level mechanical } \\
\text { allodynia }\end{array}$ & Mao et al., 2017b \\
\hline $\begin{array}{l}\text { Chronic constriction } \\
\text { injury (CCl) of the } \\
\text { sciatic nerves, mouse }\end{array}$ & $\uparrow$ & $\begin{array}{l}\text { Intrathecal injection } \\
\text { of CBX, Gap26 or } \\
\text { Gap27, astroglial } \\
\text { toxin pretreatment } \\
\text { of astrocytes, or } \\
\text { Cx43 siRNA }\end{array}$ & $\mathrm{HC}$ and GJC & $\begin{array}{l}\text { GJC blockade; } \\
\text { Cx43 extracellular } \\
\text { loop peptides; RNA } \\
\text { interference }\end{array}$ & $\begin{array}{l}\downarrow \text { mechanical } \\
\text { allodynia }\end{array}$ & Chen et al., 2014 \\
\hline $\mathrm{CCl}$, mouse & $\uparrow$ & - & - & - & - & $\begin{array}{l}\text { Neumann et al., } \\
2015\end{array}$ \\
\hline $\begin{array}{l}\text { Spinal nerve ligation } \\
\text { (SNL), rat }\end{array}$ & $\downarrow$ & $\begin{array}{l}\text { Intrathecal Cx43 } \\
\text { siRNA }\end{array}$ & $\mathrm{HC}$ and $\mathrm{GJC}$ & RNA interference & $\begin{array}{l}\downarrow \text { mechanical } \\
\text { hypersensitivity }\end{array}$ & Xu et al., 2014 \\
\hline $\begin{array}{l}\text { Spinal nerve ligation } \\
\text { (SNL), rat }\end{array}$ & $\uparrow$ & $\begin{array}{l}\text { Intrathecal } \\
\text { CORM-2 } \\
\text { administration }\end{array}$ & $\mathrm{HC}$ & $\begin{array}{l}\text { Release } \mathrm{CO} \text { as } \mathrm{HC} \\
\text { inhibitor }\end{array}$ & $\begin{array}{l}\downarrow \text { hyperalgesia and } \\
\text { allodynia }\end{array}$ & $\begin{array}{l}\text { Wang and Sun, } \\
2017\end{array}$ \\
\hline $\begin{array}{l}\text { Partial sciatic nerve } \\
\text { ligation (PSNL), mouse }\end{array}$ & $\downarrow$ & $\begin{array}{l}\text { Intrathecal injection } \\
\text { of an adenovirus } \\
\text { vector expressing } \\
\text { Cx43 }\end{array}$ & $\mathrm{HC}$ and $\mathrm{GJC}$ & RNA interference & $\begin{array}{l}\downarrow P S N L \text {-induced } \\
\text { mechanical } \\
\text { hypersensitivity }\end{array}$ & Morioka et al., 2015 \\
\hline PSNL, mouse & $\downarrow$ & $\begin{array}{l}\text { Intrathecal injection } \\
\text { of lycopene }\end{array}$ & $\mathrm{HC}$ and $\mathrm{GJC}$ & $\begin{array}{l}\text { Reversed } \\
\text { TNF-induced } \\
\text { downregulation of } \\
\text { Cx43 expression }\end{array}$ & $\begin{array}{l}\downarrow \text { mechanical } \\
\text { hypersensitivity }\end{array}$ & Zhang et al., 2016 \\
\hline $\begin{array}{l}\text { Inferior alveolar nerve } \\
\text { injury, rat }\end{array}$ & $\uparrow$ & $\begin{array}{l}\text { Administration of } \\
\text { Gap27 in the } \\
\text { trigeminal ganglion }\end{array}$ & $\mathrm{HC}$ & $\begin{array}{l}\text { Cx43 extracellular } \\
\text { loop peptides }\end{array}$ & $\begin{array}{l}\downarrow \text { mechanical } \\
\text { hypersensitivity }\end{array}$ & Kaji et al., 2016 \\
\hline $\begin{array}{l}\text { Chemotherapy } \\
\text { (bortezomib -induced } \\
\text { peripheral neuropathy), } \\
\text { rat }\end{array}$ & $\uparrow$ & $\begin{array}{l}\text { Intraperitoneal } \\
\text { injection of } \\
\text { minocycline and } \\
\text { CBX }\end{array}$ & GJC & $\begin{array}{l}\text { Glial activation } \\
\text { inhibitor and gap } \\
\text { junction decoupler }\end{array}$ & - & $\begin{array}{l}\text { Robinson and } \\
\text { Dougherty, } 2015\end{array}$ \\
\hline $\begin{array}{l}\text { Opioid intrathecal (i.t.) } \\
\text { administration of } \\
\text { morphine, rat }\end{array}$ & $\uparrow$ & $\begin{array}{l}\text { Intrathecal injection } \\
\text { of Gap26 }\end{array}$ & $\mathrm{HC}$ & $\begin{array}{l}\text { Cx43 extracellular } \\
\text { loop peptides }\end{array}$ & $\begin{array}{l}\downarrow \text { morphine } \\
\text { antinociceptive } \\
\text { tolerance, }\end{array}$ & Shen et al., 2014 \\
\hline $\begin{array}{l}\text { Inflammation (unilateral } \\
\text { carrageenan (CA) } \\
\text { injection), rat }\end{array}$ & $\uparrow$ & $\begin{array}{l}\text { Intrathecal injection } \\
\text { of CBX or Gap26 }\end{array}$ & $\mathrm{HC}$ and GJC & $\begin{array}{l}\text { Gap junction } \\
\text { decoupler and } \\
\text { Cx43 extracellular } \\
\text { loop peptides }\end{array}$ & $\begin{array}{l}\downarrow \text { contralateral paw } \\
\text { withdrawal } \\
\text { frequency (PWF), } \\
\text { while the ipsilateral } \\
\text { PWF was not } \\
\text { affected }\end{array}$ & Choi et al., 2017 \\
\hline $\begin{array}{l}\text { Bone Cancer Walker } \\
256 \text { tumor cells } \\
\text { inoculation into the } \\
\text { tibia, rat }\end{array}$ & $\mathrm{p}-\mathrm{C} \times 43 \uparrow$ & $\begin{array}{l}\text { Intrathecal injection } \\
\text { of Gap26 }\end{array}$ & $\mathrm{HC}$ & $\begin{array}{l}\text { Cx43 extracellular } \\
\text { loop peptides }\end{array}$ & $\begin{array}{l}\downarrow \text { mechanical } \\
\text { allodynia }\end{array}$ & Hang et al., 2016 \\
\hline $\begin{array}{l}\text { Bone Cancer } \\
\text { (intra-femoral } \\
\text { inoculation of Lewis } \\
\text { lung carcinoma cells), } \\
\text { mouse }\end{array}$ & $\uparrow$ & $\begin{array}{l}\text { Intrathecal injection } \\
\text { of } \mathrm{CBX}\end{array}$ & GJC & $\begin{array}{l}\text { Gap junction } \\
\text { decoupler }\end{array}$ & $\downarrow$ pain hypersensitivity & Yang et al., 2018 \\
\hline $\begin{array}{l}\text { Breakthrough cancer } \\
\text { pain }(B T c P), \text { mouse }\end{array}$ & $\begin{array}{l}\text { Cx43 protein } \uparrow \\
\text { p-Cx43 }\end{array}$ & $\begin{array}{l}\text { Intrathecal injection } \\
\text { of Gap26 }\end{array}$ & $\mathrm{HC}$ & $\begin{array}{l}\text { Cx43 extracellular } \\
\text { loop peptides }\end{array}$ & $\downarrow$ pain hypersensitivity & Li et al., 2017 \\
\hline
\end{tabular}

$\uparrow$ denotes upregulation; $\downarrow$ denotes downregulation; - denotes data unavailable. 


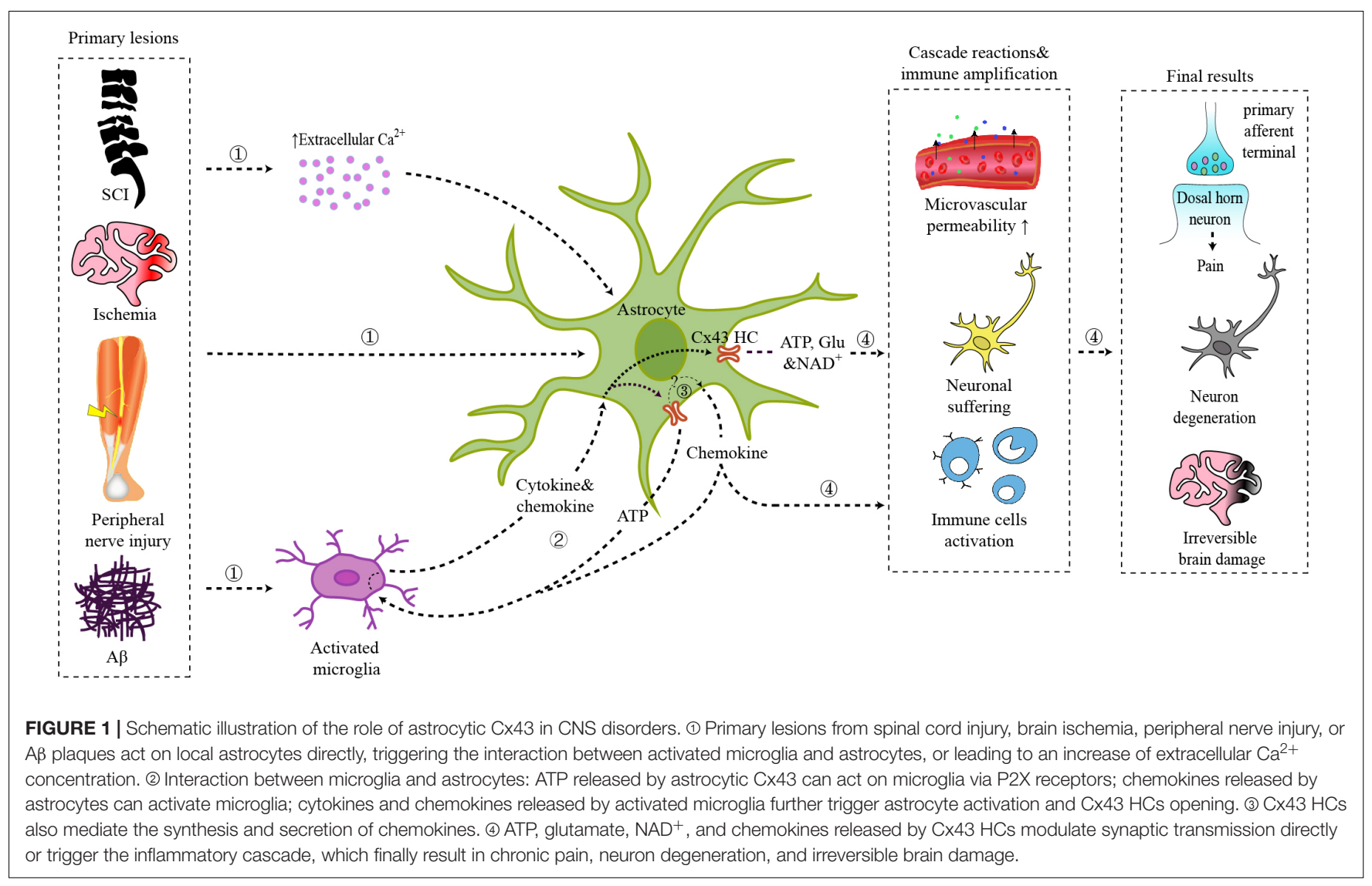

In the TMZ-resistant GBM cells, Cx43 expression showed a significant upregulation. Studies suggested that an increase of functional EGFR expression activated the JNK-ERK1/2-AP-1 axis to upregulate Cx43 expression in the TMZ-resistant GBM cells (Munoz et al., 2014). TMZ-resistance was significantly reduced when $\mathrm{Cx} 43$ was suppressed by peptides targeting $\mathrm{Cx} 43$ channels or Cx43 C-terminal (Gielen et al., 2013; Murphy et al., 2016; Grek et al., 2018), which implies TMZ-resistance is highly dependent on $\mathrm{Cx} 43$ in gliomas.

Temozolomide resistance may be mediated by $\mathrm{Cx} 43$ via the mitochondrial apoptosis pathway (Gielen et al., 2013), or interactions between $\mathrm{Cx} 43$ carboxyl terminus and actin cytoskeleton (Crespin et al., 2010). GBM cells treated with za restored TMZ sensitivity (Gielen et al., 2013; Murphy et al., 2016). These results indicated that $\mathrm{Cx} 43$ carboxyl terminus confers TMZ-resistance in gliomas. Cx43 carboxyl terminus promotes tumor cell migration, and therefore may contribute to glioma invasion (Bates et al., 2007). However, another study showed that $\mathrm{Cx} 43$ can promote tumor invasion via a carboxyl terminus-independent manner, since $\mathrm{Cx} 43$ without carboxyl terminus can also increase migration (Crespin et al., 2010), which may be derived from connexin-based $\mathrm{Ca}^{2+}$ signaling and ATP release (Sin et al., 2016). Notably, utilizing Cx43 peptidomimetics as an adjuvant for TMZ resistance has been proposed (Grek et al., 2018).

Not only does the expression of $\mathrm{Cx} 43$ change, but its role may also vary with grades, stages, and locations of the tumors. Since many studies focused on $\mathrm{Cx} 43$ in gliomas, many new therapeutic targets have been proposed (e.g., Cx43 extracellular loop, Cx43 loop/tail interactions, Cx43 C-terminal) (Delvaeye et al., 2018). The diverse effects of these drugs are needed to testify to different conditions. In addition, specific drugs targeting $\mathrm{Cx} 43$ for varying glioma, may be a better solution based on the dynamic changes of $\mathrm{Cx} 43$.

\section{Cx43 IN BRAIN ISCHEMIA}

Brain ischemia is a leading cause of long-term disability or even mortality in adults. Insufficient blood flow, which fails to meet the high metabolic demands of the brain, will trigger the cascade reaction including tissue ischemia, reperfusion injury, inflammatory activity, leading to irreversible brain damage (Kim et al., 2018). Accumulating evidence suggests that astrocytic Cx43 expression is increased after hypoxia/ischemia injury and that $\mathrm{Cx} 43$ plays an important role in cell death and neuronal damage induced by cerebral ischemia (Davidson et al., 2012a,b, 2013, 2014; Ma et al., 2018). Ischemia/reperfusion injury and the following inflammatory activation can activate the astrocytic hemichannels via the increased extracellular $\mathrm{Ca}^{2+}$ and inflammatory factors released (Davidson et al., 2013). For instance, inflammatory factors just like IL-1 $\beta$ could reverse the inhibition of hemichannel activity caused by epidermal growth factor (EGF) (Morita et al., 2007); Cx43 hemichannels can 
also be triggered via p38 kinase by pro-inflammatory cytokines including IL- $1 \beta$ and TNF- $\alpha$ released by activated microglia (Retamal et al., 2007; Giaume et al., 2013). These abnormally opened hemichannels subsequently cause an uncontrolled release of ATP, glutamate, and an overload of $\mathrm{Ca}^{2+}$, leading to tissue excitotoxicity, amplification of the inflammation (Kim et al., 2018), and ultimately irreversible brain damage. The treatment of Cx43 mimetic peptide Gap26 leads to a reduction in both $\mathrm{Cx} 43$ expression and $\mathrm{Cx} 43$ hemichannels activity, which improve neurological function and reduce infarct volume ( $\mathrm{Li}$ et al., 2015). According to this evidence, targeting to $\mathrm{Cx} 43$ might be a promising therapeutic strategy for brain ischemia, but more efforts are needed to develop specific inhibitors which can penetrate the blood-brain barrier.

\section{ASTROCYTES AND CX43 IN CHRONIC PAIN}

Astrocytes are reactive in multiple types of conditioning-induced chronic pain, including peripheral and central nerve trauma, inflammation, chronic opioid exposure, etc. (Song and Zhao, 2001; Okada-Ogawa et al., 2009; Ren and Dubner, 2010; Chiang et al., 2012; Ji et al., 2013). Consistently, inhibiting the activity of astrocytes in the spinal cord can ameliorate chronic pain (Tsuda et al., 2011). Different from rapid activation of microglia, reactive astrocytes are usually found several days after injury and persist for a longer time (Mika et al., 2009; Old et al., 2015). This indicates that astrocytes might mainly contribute to the development and maintenance of chronic pain. The following mechanisms have been discussed in the astrocyte-mediated pain: (1) astrocytes can release multiple inflammatory mediators and neuromodulators, such as cytokines IL-1 $\beta$, chemokines CCL2, and CXCL1; (2) a variety of receptors and transports, for example, ATP receptors P2XR and P2Y, glutamate transporter-1 (GLT-1), and glutamate and aspartic acid transporter (GLAST) can be activated in astrocytes; (3) the mitogen activated protein kinases (MAPKs) are also activated and further induce downstream signaling critical for pain; (4) reactive astrocytes also regulate the opening states of gap junctions or hemichannels, which further control the release of ATP, glutamate, and $\mathrm{NAD}^{+}$. These signaling pathways coordinate or interact with each other in response to pain. The role of $\mathrm{Cx} 43$ in pain is acknowledged by the study that $\mathrm{Cx} 43 / \mathrm{Cx} 30$ deletion, instead of $\mathrm{C} \times 30$ single knockout, can alleviate the neuropathic pain developed between 4 and 8 weeks following spinal cord injury (Chen et al., 2012). Here, we will comprehensively discuss the role of $\mathrm{Cx} 43$ in chronic pain.

Studies have shown that $\mathrm{Cx} 43$ can act as a non-ligated hemichannel releasing small mediators or gliotransmitters, such as ATP and glutamate, into the extracellular environment (Bennett et al., 2003; D'hondt et al., 2014), which modulate synaptic transmission by directly interacting with nociceptive neurons, further contributing to pain. In addition, extracellular ATP also acts via its receptor P2X on non-neuronal cells, which contribute to pain by inducing the release of cytokines and chemokines.
Studies have shown that $\mathrm{Cx} 43$ can also regulate the expression or secretion of cytokines and chemokines in multiple systems. Although it is generally believed that hemichannels only allow passage of small molecules and ions, it has been reported that $\mathrm{Cx} 43$ can control the secretion of chemokine CXCL12 in bone marrow stromal cells (Schajnovitz et al., 2011). In the rat arthritis model, LPS treatment significantly enhanced Cx43 gene expression in rat fibroblast-like synoviocytes, whereas transfection of siCx 43 inhibited the LPS-induced overexpression of pro-inflammatory cytokines and chemokines (Tsuchida et al., 2013). Furthermore, CBX (carbenoxolone, a non-selective gapjunction inhibitor) reduces the increase of IL-1 $\beta$ and IL6 in cerebrospinal fluid caused by intrathecal injection of HIV1 gp120 (Spataro et al., 2004). The expression and secretion of cytokines or chemokines are up-regulated in TNF- $\alpha$-activated astrocytes, which are important in the induction and maintenance of pain hypersensitivity (Gao et al., 2009; Huh et al., 2017). Our previous study has shown that TNF- $\alpha$-induced CXCL1 and CCL2 release from astrocytes, were blocked by $\mathrm{Cx} 43$ small interfering RNA, CBX and ${ }^{43} \mathrm{Gap} 26$ or ${ }^{37,43} \mathrm{Gap} 27$ (two Cx43 mimetic peptides that blocks hemichannels), indicating that astrocytic Cx43 hemichannels are responsible for the release of the chemokines (Chen et al., 2014). Another study showed that intrathecal injection of ${ }^{43} \mathrm{Gap} 26$ markedly attenuated mechanical allodynia in rat bone cancer model and reduced CXCL12 production from spinal dorsal horn in astrocytes (Hang et al., 2016). Although this evidence suggests that $\mathrm{Cx} 43$ hemichannels mediate the synthesis and secretion of chemokines, the mechanism remains unclear as chemokines are too large to directly efflux through the Cx43 hemichannels. One possible explanation is that activated calcium signaling contributes to CXCL12 secretion via the GTPase RalA (Schajnovitz et al., 2011). Another possibility is that an increase of purine induced by $\mathrm{Cx} 43$ may regulate the release of chemokines, based on the role of purinergic signaling in astrocytic release (Chen et al., 2014). Moreover, the Cx43 hemichannel may be hyperactive in pathological conditions, thereby causing chemokines to "leak" out of astrocytes through cytoskeletal changes (Cotrina et al., 2000).

The expression changes of $\mathrm{Cx} 43$ following pain is still inconclusive (Table 2). Multiple studies have shown that $\mathrm{Cx} 43$ is upregulated in astrocytes following nerve ligation and spinal cord injury, and that inhibition of $\mathrm{Cx} 43$ can attenuate pain hypersensitivity (Wu et al., 2011; Chen et al., 2012, 2014, 2018; Shen et al., 2014; Neumann et al., 2015; Robinson and Dougherty, 2015; Choi et al., 2016; Hang et al., 2016; Kaji et al., 2016; Mao et al., 2017a,b; Wang and Sun, 2017; Yang et al., 2018). On the contrary, few studies showed that a decrease of Cx43 following nerve injury could contribute to pain hypersensitivity (Xu et al., 2014; Morioka et al., 2015; Zhang et al., 2016). Interestingly, in a mouse model of breakthrough cancer pain, $\mathrm{Cx} 43$ protein level is upregulated while phosphorylation of $\mathrm{Cx} 43$ (p-Cx43) is downregulated ( $\mathrm{Li}$ et al., 2017). The conflict might come from distinct pain conditions or models. Additionally, it might not be the $\mathrm{Cx} 43$ expression level alone that determines the enhanced or attenuated function of hemichannels or gap junctions, because even in the pain model with decreased CX43 
expression, inhibition of CX43 function can still relieve pain (Xu et al., 2014).

Studies have shown that $\mathrm{Cx} 43$ can be highly regulated by astrocytic inflammatory mediators, growth factors, or receptors. TNF- $\alpha$ and IL- $1 \beta$, inflammatory mediators produced by astrocytes in pain, can modulate the expression of $\mathrm{Cx} 43$ (Morioka et al., 2015; Choi et al., 2017). For example, TNF decreases $\mathrm{Cx} 43$ expression in naive mice, which can be reversed by the TNF inhibitor (Morioka et al., 2015). Reactive astrocytes also lead to an increase in the basic fibroblast growth factor (bFGF or FGF-2) in the late phase following nerve injury. bFGF increases the expression of $\mathrm{Cx} 43$ and enhances intercellular communication of $\mathrm{Cx} 43$ gap junction in cardiac fibroblasts (Doble and Kardami, 1995), though the study of the role of bFGF in astrocytic Cx43 is lacking. In addition, the sigma-1 receptor activated by astrocytes in both peripheral and central neuropathy, could also modulate the activation of $\mathrm{Cx} 43$. The increase in $\mathrm{Cx} 43$ expression can be reversed by a sigma-1 receptor blocker (Choi et al., 2016).

Increasing evidence has shown that mitogen-activated protein kinases (MAPKs) can also regulate the opening states of $\mathrm{Cx} 43$ channels in astrocytes. Activation of MAPKs family members contribute to pain sensitization. For instance, extracellular signalregulated kinases (ERKs) is significantly upregulated in astrocytes when animals were injected with complete Freund's adjuvant (CFA), a drug inducing inflammation and pain (Weyerbacher et al., 2010). Phosphorylation of C-Jun N-terminal kinases (JNKs), predominantly JNK-1, is observed in spinal astrocytes in a persistent pain condition (Gao et al., 2010). MAPKs lead to a closure of CX43 gap junction and hemichannels, while MAPK phosphatase make Cx43 preferentially open (Kim et al., 1999; Goodenough and Paul, 2003; Solan and Lampe, 2005). Notably, phosphorylation and dephosphorylation events not only regulate the gating of channels, but also the trafficking and assembly of connexins (Ribeiro-Rodrigues et al., 2017), indicating the complicated effects of MAPKs on Cx43.

Though the interaction between $\mathrm{Cx} 43$ and molecules involved in pain offers a complicated feedback loop in pain development and maintenance, based on the current studies, strategies to suppress the function of $\mathrm{Cx} 43$ may be a robust approach for pain relief (Wu et al., 2011; Chen et al., 2012, 2014; Shen et al., 2014; Xu et al., 2014; Neumann et al., 2015; Robinson and Dougherty, 2015; Choi et al., 2016; Hang et al., 2016; Kaji et al., 2016; Mao et al., 2017a,b; Wang and Sun, 2017; Yang et al., 2018).

Cx43 might function as hemichannels or a gap junction, which has not been clearly characterized in every single study (Tables 1, 2). A non-selective gap-junction inhibitor carbenoxolone (CBX) can reduces neuropathic pain (Wang et al., 2014), supporting the ideas that $\mathrm{Cx} 43$ can function as a gap junction. On the other hand, studies proposed a model in which $\mathrm{Cx} 43$ can function as a non-junctional hemichannel to release mediators such as ATP and glutamate (Bennett et al., 2003; D'hondt et al., 2014). There are a few ways to distinguish hemichannels and gap junctions. For example, when used for short incubation time or at a low concentration, peptide 5 , a mimetic of $\mathrm{Cx} 43$, can only inhibit hemichannels, but when applied for a long incubation time or at a long concentration, can attenuate both hemichannels and gap junctions (Choi et al., 2016; Mao et al., 2017a). Another approach to distinguish $\mathrm{Cx} 43$ gap junction and hemichannels are using the dyes uptaken. Lucifer yellow, only permeable to the gap junction, while ethidium bromide is considered exclusively uptaken by hemichannels. The diffusion rates of these dyes will differentiate hemichannel and gap junction. Interestingly, a peptide derived from the cytoplasmic loop of Cx43 termed Gap19 can specifically function in $\mathrm{Cx} 43$ hemichannels while not affecting gap junctions (Abudara et al., 2014). In addition, La3+ can specifically block hemichannels rather than gap junctions. Typically, the use of these drugs is accompanied by other blockers or dyes, however, thus far no drugs that only target to $\mathrm{Cx} 43$ are available.

The enriched expression of $\mathrm{Cx} 43$ and wide distribution of astrocytes in the brain and spinal cord might explain the complicated phenotypes observed in animals with $\mathrm{Cx} 43$ manipulation. Though changes of either ATP, glutamate, or $\mathrm{Ca}^{2+}$ can be detected when $\mathrm{Cx} 43$ is manipulated, it is hard to tell how each molecule contributes to the system since (1) few studies have systematically tested all changes of these molecules; (2) not only local signaling is affected by these small molecules.

\section{CONCLUSION AND PERSPECTIVES}

Astrocytes modulate extrasynaptic or synaptic milieu to further enhance or dampen electrochemical signaling propagating in neurons. As the major connexin altered following nerve injury, Cx43 can be regulated by multiple signals under pathological conditions, which in turn, modulate several downstream signals critical for neuronal activity, and further contribute to a variety of CNS disorders, including pain. So far, up to 21 phosphorylation sites have been reported in Cx43 (Pogoda et al., 2016), indicating a complex post-translational modification. Further studies might be necessary to characterize how these phosphorylation sites contribute to specific CNS disorders. Of note, besides connexin hemichannels, pannexin is also detectable in astrocytes (Garre et al., 2010). Pannexin-1, like Cx43, can also be inhibited by the non-selective gap-junction blocker CBX (Garre et al., 2010). Therefore, the role of Pannexin-1 in pain control could be an interesting topic to explore. In addition, how connexins interact with pannexins and the signaling pathways mediated by connexins or pannexins need further investigation. Selective manipulation of connexins might be a potential therapeutic approach in some CNS disorders.

\section{AUTHOR CONTRIBUTIONS}

LX and TY wrote and drafted the manuscript. All authors contributed to manuscript revision, read and approved the submitted version.

\section{FUNDING}

This study was supported by The National Key Research and Development Program of China (2017YFA0104704 and 
2016YFC1101602), The National Natural Science Foundation of China (31872773, 81701127, and 81671220), The Natural Science Foundation of JiangSu of China (BK20170446 and BK20181460), The Natural Science Foundation of the JiangSu Higher Education

\section{REFERENCES}

Abudara, V., Bechberger, J., Freitas-Andrade, M., De Bock, M., Wang, N., Bultynck, G., et al. (2014). The connexin43 mimetic peptide Gap19 inhibits hemichannels without altering gap junctional communication in astrocytes. Front. Cell. Neurosci. 8:306. doi: 10.3389/fncel.2014.00306

Almad, A. A., Doreswamy, A., Gross, S. K., Richard, J. P., Huo, Y., Haughey, N., et al. (2016). Connexin 43 in astrocytes contributes to motor neuron toxicity in amyotrophic lateral sclerosis. Glia 64, 1154-1169. doi: 10.1002/glia.22989

Ballard, C., Gauthier, S., Corbett, A., Brayne, C., Aarsland, D., and Jones, E. (2011). Alzheimer's disease. Lancet 377, 1019-1031. doi: 10.1016/S0140-6736(10) 61349-9

Bates, D. C., Sin, W. C., Aftab, Q., and Naus, C. C. (2007). Connexin43 enhances glioma invasion by a mechanism involving the carboxy terminus. Glia 55 , 1554-1564. doi: 10.1002/glia.20569

Batra, N., Riquelme, M. A., Burra, S., and Jiang, J. X. (2014). 14-3-30 facilitates plasma membrane delivery and function of mechanosensitive connexin 43 hemichannels. J. Cell Sci. 127, 137-146. doi: 10.1242/jcs.133553

Bennett, B. C., Purdy, M. D., Baker, K. A., Acharya, C., McIntire, W. E., Stevens, R. C., et al. (2016). An electrostatic mechanism for $\mathrm{Ca}^{2+}$ mediated regulation of gap junction channels. Nat. Commun. 7:8770. doi: 10.1038/ncomms 9770

Bennett, M. V. L., Contreras, J. E., Bukauskas, F. F., and Sáez, J. C. (2003). New roles for astrocytes: gap junction hemichannels have something to communicate. Trends Neurosci. 26, 610-617. doi: 10.1016/j.tins.2003.09.008

Cabezas, R., Avila, M., Gonzalez, J., El-Bachá, R. S., Báez, E., GarcÃ-a-Segura, L. M., et al. (2014). Astrocytic modulation of blood brain barrier: perspectives on Parkinson's disease. Front. Cell. Neurosci. 8:211. doi: 10.3389/fncel.2014.00211

Castellano, P., and Eugenin, E. A. (2014). Regulation of gap junction channels by infectious agents and inflammation in the CNS. Front. Cell. Neurosci. 8:122. doi: 10.3389/fncel.2014.00122

Chen, G., Luo, X., Qadri, M. Y., Berta, T., and Ji, R. R. (2018). Sex-dependent glial signaling in pathological pain: distinct roles of spinal microglia and astrocytes. Neurosci. Bull. 34, 98-108. doi: 10.1007/s12264-017-0145-y

Chen, G., Park, C. K., Xie, R. G., Berta, T., Nedergaard, M., and Ji, R. R. (2014). Connexin-43 induces chemokine release from spinal cord astrocytes to maintain late-phase neuropathic pain in mice. Brain 137, 2193-2209. doi: 10.1093/brain/awu140

Chen, M. J., Kress, B., Han, X., Moll, K., Peng, W., Ji, R.-R., et al. (2012). Astrocytic Cx43 hemichannels and gap junctions play a crucial role in development of chronic neuropathic pain following spinal cord injury. Glia 60, 1660-1670. doi: 10.1002/glia.22384

Chiang, C.-Y., Sessle, B. J., and Dostrovsky, J. O. (2012). Role of astrocytes in pain. Neurochem. Res. 37, 2419-2431. doi: 10.1007/s11064-012-0801-6

Choi, H.-S., Roh, D.-H., Yoon, S.-Y., Kwon, S.-G., Choi, S.-R., Kang, S.-Y., et al. (2017). The role of spinal interleukin-1 $\beta$ and astrocyte connexin 43 in the development of mirror-image pain in an inflammatory pain model. Exp. Neurol. 287, 1-13. doi: 10.1016/j.expneurol.2016.10.012

Choi, S.-R., Roh, D.-H., Yoon, S.-Y., Kwon, S.-G., Choi, H.-S., Han, H.-J., et al. (2016). Astrocyte sigma-1 receptors modulate connexin 43 expression leading to the induction of below-level mechanical allodynia in spinal cord injured mice. Neuropharmacology 111, 34-46. doi: 10.1016/j.neuropharm.2016.08.027

Cotrina, M. L., Lin, J. H., López-García, J. C., Naus, C. C., and Nedergaard, M. (2000). ATP-mediated glia signaling. J. Neurosci. 20, 2835-2844. doi: 10.1523/ JNEUROSCI.20-08-02835.2000

Crespin, S., Bechberger, J., Mesnil, M., Naus, C. C., and Sin, W. C. (2010). The carboxy-terminal tail of connexin 43 gap junction protein is sufficient to mediate cytoskeleton changes in human glioma cells. J. Cell. Biochem. 110, 589-597. doi: $10.1002 /$ jcb. 22554

Danesh-Meyer, H. V., Kerr, N. M., Zhang, J., Eady, E. K., O’Carroll, S. J., Nicholson, L. F. B., et al. (2012). Connexin43 mimetic peptide reduces vascular leak and
Institutions of China (17KJA180009), the Jilin Scientific and Technological Development Program (20160101077JC), and the Jilin Provincial School Joint Construction Special Project (SXGJQY2017-13).

retinal ganglion cell death following retinal ischaemia. Brain, 135, 506-520. doi: 10.1093/brain/awr338

Davidson, J. O., Drury, P. P., Green, C. R., Nicholson, L. F., Bennet, L., and Gunn, A. J. (2014). Connexin hemichannel blockade is neuroprotective after asphyxia in preterm fetal sheep. PLoS One 9:e96558. doi: 10.1371/journal.pone.009 6558

Davidson, J. O., Green, C. R., Bennet, L., Nicholson, L. F., Danesh-Meyer, H., O'Carroll, S. J., et al. (2013). A key role for connexin hemichannels in spreading ischemic brain injury. Curr. Drug Targets 14, 36-46. doi: 10.2174/ 138945013804806479

Davidson, J. O., Green, C. R., Louise, L. F., O’Carroll, S. J., Fraser, M., Bennet, L., et al. (2012a). Connexin hemichannel blockade improves outcomes in a model of fetal ischemia. Ann. Neurol. 71, 121-132. doi: 10.1002/ana.22654

Davidson, J. O., Green, C. R., Nicholson, L. F. B., Bennet, L., and Gunn, A. J. (2012b). Deleterious effects of high dose connexin 43 mimetic peptide infusion after cerebral ischaemia in near-term fetal sheep. Int. J. Mol. Sci. 13, 6303-6319. doi: 10.3390/ijms13056303

Decrock, E., Vinken, M., Bol, M., D’Herde, K., Rogiers, V., Vandenabeele, P., et al. (2011). Calcium and connexin-based intercellular communication, a deadly catch? Cell Calcium 50, 310-321. doi: 10.1016/j.ceca.2011.05.007

Delvaeye, T., Vandenabeele, P., Bultynck, G., Leybaert, L., and Krysko, D. V. (2018). Therapeutic targeting of connexin channels: new views and challenges. Trends Mol. Med. 24, 1036-1053. doi: 10.1016/j.molmed.2018.10.005

D’hondt, C., Iyyathurai, J., Himpens, B., Leybaert, L., and Bultynck, G. (2014). Cx43-hemichannel function and regulation in physiology and pathophysiology: insights from the bovine corneal endothelial cell system and beyond. Front. Physiol. 5:348. doi: 10.3389/fphys.2014.00348

Doble, B. W., and Kardami, E. (1995). Basic fibroblast growth factor stimulates connexin-43 expression and intercellular communication of cardiac fibroblasts. Mol. Cell. Biochem. 143, 81-87. doi: 10.1007/BF00925930

Fernandez, H. H. (2012). Updates in the medical management of Parkinson disease. Cleve. Clin. J. Med. 79, 28-35. doi: 10.3949/ccjm.78gr.11005

Freitas-Andrade, M., and Naus, C. C. (2016). Astrocytes in neuroprotection and neurodegeneration: the role of connexin 43 and pannexin1. Neuroscience 323, 207-221. doi: 10.1016/j.neuroscience.2015.04.035

Gajardo-Gómez, R., Labra, V. C., Maturana, C. J., Shoji, K. F., Santibañez, C. A., Sáez, J. C., et al. (2017). Cannabinoids prevent the amyloid $\beta$-induced activation of astroglial hemichannels: a neuroprotective mechanism. Glia 65, 122-137. doi: 10.1002/glia.23080

Gao, Y.-J., Xu, Z.-Z., Liu, Y.-C., Wen, Y.-R., Decosterd, I., and Ji, R.-R. (2010). The c-Jun N-terminal kinase 1 (JNK1) in spinal astrocytes is required for the maintenance of bilateral mechanical allodynia under a persistent inflammatory pain condition. Pain 148, 309-319. doi: 10.1016/j.pain.2009.11.017

Gao, Y.-J., Zhang, L., Samad, O. A., Suter, M. R., Yasuhiko, K., Xu, Z.-Z., et al. (2009). JNK-induced MCP-1 production in spinal cord astrocytes contributes to central sensitization and neuropathic pain. J. Neurosci. 29, 4096-4108. doi: 10.1523/JNEUROSCI.3623-08.2009

Garre, J. M., Retamal, M. A., Cassina, P., Barbeito, L., Bukauskas, F. F., Saez, J. C., et al. (2010). FGF-1 induces ATP release from spinal astrocytes in culture and opens pannexin and connexin hemichannels. Proc. Natl. Acad. Sci. U.S.A. 107, 22659-22664. doi: 10.1073/pnas.1013793107

Giaume, C., Leybaert, L., Naus, C. C., and Sáez, J. C. (2013). Connexin and pannexin hemichannels in brain glial cells: properties, pharmacology, and roles. Front. Pharmacol. 4:88. doi: 10.3389/fphar.2013.00088

Gielen, P. R., Aftab, Q., Ma, N., Chen, V. C., Hong, X., Lozinsky, S., et al. (2013). Connexin43 confers temozolomide resistance in human glioma cells by modulating the mitochondrial apoptosis pathway. Neuropharmacology 75 , 539-548. doi: 10.1016/j.neuropharm.2013.05.002

Goodenough, D. A., and Paul, D. L. (2003). Beyond the gap: functions of unpaired connexon channels. Nat. Rev. Mol. Cell Biol. 4, 285-295. doi: 10.1038/nrm1072 
Grek, C. L., Sheng, Z., Naus, C. C., Sin, W. C., Gourdie, R. G., and Ghatnekar, G. G. (2018). Novel approach to temozolomide resistance in malignant glioma: connexin43-directed therapeutics. Curr. Opin. Pharmacol. 41, 79-88. doi: 10. 1016/j.coph.2018.05.002

Hang, L.-H., Li, S.-N., Luo, H., Shu, W.-W., Mao, Z.-M., Chen, Y.-F., et al. (2016). Connexin 43 mediates CXCL12 production from spinal dorsal horn to maintain bone cancer pain in rats. Neurochem. Res. 41, 1200-1208. doi: 10.1007/s11064015-1815-7

Hawat, G., Benderdour, M., Rousseau, G., and Baroudi, G. (2010). Connexin 43 mimetic peptide Gap26 confers protection to intact heart against myocardial ischemia injury. Pflugers Arch. Eur. J. Physiol. 460, 583-592. doi: 10.1007/ s00424-010-0849-6

Hirayama, Y., and Koizumi, S. (2018). Astrocytes and ischemic tolerance. Neurosci. Res. 126, 53-59. doi: 10.1016/j.neures.2017.11.013

Huh, Y., Ji, R.-R., and Chen, G. (2017). Neuroinflammation, bone marrow stem cells, and chronic pain. Front. Immunol. 8:1014. doi: 10.3389/fimmu.2017.01014

Ji, R.-R., Berta, T., and Nedergaard, M. (2013). Glia and pain: is chronic pain a gliopathy? Pain 154(Suppl.), S10-28. doi: 10.1016/j.pain.2013.06.022

Johansen, D., Cruciani, V., Sundset, R., Ytrehus, K., and Mikalsen, S.-O. (2011). Ischemia induces closure of gap junctional channels and opening of hemichannels in heart-derived cells and tissue. Cell. Physiol. Biochem. 28, 103-114. doi: 10.1159/000331719

Kaji, K., Shinoda, M., Honda, K., Unno, S., Shimizu, N., and Iwata, K. (2016). Connexin 43 contributes to ectopic orofacial pain following inferior alveolar nerve injury. Mol. Pain 12, 1-12. doi: 10.1177/1744806916633704

Kim, D. Y., Kam, Y., Koo, S. K., and Joe, C. O. (1999). Gating connexin 43 channels reconstituted in lipid vesicles by mitogen-activated protein kinase phosphorylation. J. Biol. Chem. 274, 5581-5587. doi: 10.1074/jbc.274.9.5581

Kim, Y., Davidson, J. O., Green, C. R., Nicholson, L. F. B., O'Carroll, S. J., and Zhang, J. (2018). Connexins and pannexins in cerebral ischemia. Biochim. Biophys. Acta-Biomembr. 1860, 224-236. doi: 10.1016/j.bbamem.2017.03.018

Koulakoff, A., Mei, X., Orellana, J. A., Sáez, J. C., and Giaume, C. (2012). Glial connexin expression and function in the context of Alzheimer's disease. Biochim. Biophys. Acta - Biomembr. 1818, 2048-2057. doi: 10.1016/j.bbamem. 2011.10.001

Lapato, A. S., and Tiwari-Woodruff, S. K. (2018). Connexins and pannexins: at the junction of neuro-glial homeostasis \& disease. J. Neurosci. Res. 96, 31-44. doi: $10.1002 /$ jnr. 24088

Li, T., Giaume, C., and Xiao, L. (2014). Connexins-mediated glia networking impacts myelination and remyelination in the central nervous system. Mol. Neurobiol. 49, 1460-1471. doi: 10.1007/s12035-013-8625-1

Li, X., Jiang, S., Yang, H., Liao, Q., Cao, S., Yan, X., et al. (2017). Breakthrough cancer pain is associated with spinal gap junction activation via regulation of connexin 43 in a mouse model. Front. Cell. Neurosci. 11:207. doi: 10.3389/fncel. 2017.00207

Li, X., Zhao, H., Tan, X., Kostrzewa, R. M., Du, G., Chen, Y., et al. (2015). Inhibition of connexin43 improves functional recovery after ischemic brain injury in neonatal rats. Glia 63, 1553-1567. doi: 10.1002/glia.22826

Ma, D., Feng, L., Cheng, Y., Xin, M., You, J., Yin, X., et al. (2018). Astrocytic gap junction inhibition by carbenoxolone enhances the protective effects of ischemic preconditioning following cerebral ischemia. J. Neuroinflamm. 15, 1-12. doi: 10.1186/s12974-018-1230-5

Mao, Y., Nguyen, T., Tonkin, R. S., Lees, J. G., Warren, C., O’Carroll, S. J., et al. (2017a). Characterisation of Peptide5 systemic administration for treating traumatic spinal cord injured rats. Exp. Brain Res. 235, 3033-3048. doi: 10.1007/ s00221-017-5023-3

Mao, Y., Tonkin, R. S., Nguyen, T., O’Carroll, S. J., Nicholson, L. F. B., Green, C. R., et al. (2017b). Systemic administration of connexin 43 mimetic peptide improves functional recovery after traumatic spinal cord injury in adult rats. J. Neurotrauma 34, 707-719. doi: 10.1089/neu.2016.4625

Mei, X., Ezan, P., Giaume, C., and Koulakoff, A. (2010). Astroglial connexin immunoreactivity is specifically altered at $\beta$-amyloid plaques in $\beta$-amyloid precursor protein/presenilin1 mice. Neuroscience 171, 92-105. doi: 10.1016/j. neuroscience.2010.08.001

Mika, J., Osikowicz, M., Rojewska, E., Korostynski, M., Wawrzczak-Bargiela, A., Przewlocki, R., et al. (2009). Differential activation of spinal microglial and astroglial cells in a mouse model of peripheral neuropathic pain. Eur. J. Pharmacol. 623, 65-72. doi: 10.1016/j.ejphar.2009.09.030
Morioka, N., Zhang, F. F., Nakamura, Y., Kitamura, T., Hisaoka-Nakashima, K., and Nakata, Y. (2015). Tumor necrosis factor-mediated downregulation of spinal astrocytic connexin43 leads to increased glutamatergic neurotransmission and neuropathic pain in mice. Brain. Behav. Immun. 49, 293-310. doi: 10.1016/j.bbi.2015.06.015

Morita, M., Saruta, C., Kozuka, N., Okubo, Y., Itakura, M., Takahashi, M., et al. (2007). Dual regulation of astrocyte gap junction hemichannels by growth factors and a pro-inflammatory cytokine via the mitogen-activated protein kinase cascade. Glia 55, 508-515. doi: 10.1002/glia.20471

Munoz, J. L., Rodriguez-Cruz, V., Greco, S. J., Ramkissoon, S. H., Ligon, K. L., and Rameshwar, P. (2014). Temozolomide resistance in glioblastoma cells occurs partly through epidermal growth factor receptormediated induction of connexin 43. Cell Death Dis. 5:e1145. doi: 10.1038/cddis.2014.111

Murphy, S. F., Varghese, R. T., Lamouille, S., Guo, S., Pridham, K. J., Kanabur, P., et al. (2016). Connexin 43 inhibition sensitizes chemoresistant glioblastoma cells to temozolomide. Cancer Res. 76, 139-149. doi: 10.1158/0008-5472.CAN15- 1286

Nagy, J. I., Li, W., Hertzberg, E. L., and Marotta, C. A. (1996). Elevated connexin43 immunoreactivity at sites of amyloid plaques in Alzheimer's disease. Brain Res. 717, 173-178. doi: 10.1016/0006-8993(95)01526-4

Neumann, E., Hermanns, H., Barthel, F., Werdehausen, R., and Brandenburger, T. (2015). Expression changes of microRNA-1 and its targets connexin 43 and brain-derived neurotrophic factor in the peripheral nervous system of chronic neuropathic rats. Mol. Pain 11, 1-9. doi: 10.1186/s12990-015-0045-y

Okada-Ogawa, A., Suzuki, I., Sessle, B. J., Chiang, C.-Y., Salter, M. W., Dostrovsky, J. O., et al. (2009). Astroglia in medullary dorsal horn (trigeminal spinal subnucleus caudalis) are involved in trigeminal neuropathic pain mechanisms. J. Neurosci. 29, 11161-11171. doi: 10.1523/JNEUROSCI.3365-09. 2009

Old, E. A., Clark, A. K., and Malcangio, M. (2015). The role of glia in the spinal cord in neuropathic and inflammatory pain. Handb. Exp. Pharmacol. 227, 145-170. doi: 10.1007/978-3-662-46450-2_8

Orellana, J. A. (2016). Physiological functions of glial cell hemichannels. Adv. Exp. Med. Biol. 949, 93-108. doi: 10.1007/978-3-319-40764-7_5

Orellana, J. A., Retamal, M. A., Moraga-Amaro, R., and Stehberg, J. (2016). Role of astroglial hemichannels and pannexons in memory and neurodegenerative diseases. Front. Integr. Neurosci. 10:26. doi: 10.3389/fnint.2016.00026

Orellana, J. A., Shoji, K. F., Abudara, V., Ezan, P., Amigou, E., Saez, P. J., et al. (2011). Amyloid-induced death in neurons involves glial and neuronal hemichannels. J. Neurosci. 31, 4962-4977. doi: 10.1523/JNEUROSCI.6417-10. 2011

Pascual, O. (2005). Astrocytic purinergic signaling coordinates synaptic networks. Science (80-). 310, 113-116. doi: 10.1126/science.1116916

Pogoda, K., Kameritsch, P., Retamal, M. A., and Vega, J. L. (2016). Regulation of gap junction channels and hemichannels by phosphorylation and redox changes: a revision. BMC Cell Biol. 17:11. doi: 10.1186/s12860-016-0099-3

Rash, J. E., Yasumura, T., Davidson, K. G., Furman, C. S., Dudek, F. E., and Nagy, J. I. (2001a). Identification of cells expressing Cx43, Cx30, Cx26, Cx32 and Cx36 in gap junctions of rat brain and spinal cord. Cell Commun. Adhes 8, 315-320. doi: 10.3109/15419060109080745

Rash, J. E., Yasumura, T., Dudek, F. E., and Nagy, J. I. (2001b). Cell-specific expression of connexins and evidence of restricted gap junctional coupling between glial cells and between neurons. J. Neurosci. 21, 1983-2000. doi: 10 . 1523/JNEUROSCI.21-06-01983.2001

Ren, K., and Dubner, R. (2010). Interactions between the immune and nervous systems in pain. Nat. Med. 16, 1267-1276. doi: 10.1038/nm.2234

Ren, R., Zhang, L., and Wang, M. (2018). Specific deletion connexin43 in astrocyte ameliorates cognitive dysfunction in APP/PS1 mice. Life Sci. 208, 175-191. doi: 10.1016/j.lfs.2018.07.033

Retamal, M. A., Alcayaga, J., Verdugo, C. A., Bultynck, G., Leybaert, L., Sáez, P. J., et al. (2014). Opening of pannexin- and connexin-based channels increases the excitability of nodose ganglion sensory neurons. Front. Cell. Neurosci. 8:158. doi: $10.3389 /$ fncel.2014.00158

Retamal, M. A., Froger, N., Palacios-Prado, N., Ezan, P., Saez, P. J., Saez, J. C., et al. (2007). Cx43 hemichannels and gap junction channels in astrocytes are regulated oppositely by proinflammatory cytokines released from activated microglia. J. Neurosci. 27, 13781-13792. doi: 10.1523/JNEUROSCI.2042-07. 2007 
Retamal, M. A., Reyes, E. P., García, I. E., Pinto, B., Martínez, A. D., and González, C. (2015). Diseases associated with leaky hemichannels. Front. Cell. Neurosci. 9:267. doi: 10.3389/fncel.2015.00267

Ribeiro-Rodrigues, T. M., Nia Martins-Marques, T., Morel, S., Kwak, B. R., and Gira, H. (2017). Role of connexin 43 in different forms of intercellular communication-gap junctions, extracellular vesicles and tunnelling nanotubes. J. Cell Sci. 130, 3619-3630. doi: 10.1242/jcs.200667

Robinson, C. R., and Dougherty, P. M. (2015). Spinal astrocyte gap junction and glutamate transporter expression contributes to a rat model of bortezomibinduced peripheral neuropathy. Neuroscience 285, 1-10. doi: 10.1016/j. neuroscience.2014.11.009

Rodríguez, J. J., Olabarria, M., Chvatal, A., and Verkhratsky, A. (2009). Astroglia in dementia and Alzheimer's disease. Cell Death Differ. 16, 378-385. doi: 10.1038/ cdd.2008.172

Saez, J. C., Berthoud, V. M., Branes, M. C., Martinez, A. D., and Beyer, E. C. (2003). Plasma membrane channels formed by connexins: their regulation and functions. Physiol. Rev. 83, 1359-1400. doi: 10.1152/physrev.00007.2003

Schajnovitz, A., Itkin, T., D’Uva, G., Kalinkovich, A., Golan, K., Ludin, A., et al. (2011). CXCL12 secretion by bone marrow stromal cells is dependent on cell contact and mediated by connexin-43 and connexin-45 gap junctions. Nat. Immunol. 12, 391-398. doi: 10.1038/ni.2017

Scott, C. A., Tattersall, D., O’Toole, E. A., and Kelsell, D. P. (2012). Connexins in epidermal homeostasis and skin disease. Biochim. Biophys. Acta - Biomembr. 1818, 1952-1961. doi: 10.1016/J.BBAMEM.2011.09.004

Shen, N., Mo, L.-Q., Hu, F., Chen, P.-X., Guo, R.-X., and Feng, J.-Q. (2014). A novel role of spinal astrocytic connexin 43: mediating morphine antinociceptive tolerance by activation of NMDA receptors and inhibition of glutamate transporter-1 in rats. CNS Neurosci. Ther. 20, 728-736. doi: 10.1111/cns.12244

Sin, W. C., Aftab, Q., Bechberger, J. F., Leung, J. H., Chen, H., and Naus, C. C. (2016). Astrocytes promote glioma invasion via the gap junction protein connexin43. Oncogene 35, 1504-1516. doi: 10.1038/onc.2015.210

Sin, W. C., Crespin, S., and Mesnil, M. (2012). Opposing roles of connexin43 in glioma progression. Biochim. Biophys. Acta - Biomembr. 1818, 2058-2067. doi: 10.1016/j.bbamem.2011.10.022

Solan, J. L., and Lampe, P. D. (2005). Connexin phosphorylation as a regulatory event linked to gap junction channel assembly. Biochim. Biophys. Acta Biomembr. 1711, 154-163. doi: 10.1016/J.BBAMEM.2004.09.013

Song, P., and Zhao, Z. Q. (2001). The involvement of glial cells in the development of morphine tolerance. Neurosci. Res. 39, 281-286. doi: 10.1016/S0168-0102(00) 00226- 1

Sontheimer, H. (2015). Brain cancer: tumour cells on neighbourhood watch. Nature 528, 49-50. doi: 10.1038/nature15649

Spataro, L. E., Sloane, E. M., Milligan, E. D., Wieseler-Frank, J., Schoeniger, D., Jekich, B. M., et al. (2004). Spinal gap junctions: potential involvement in pain facilitation. J. Pain 5, 392-405. doi: 10.1016/J.JPAIN.2004.06.006

Stupp, R., Mason, W., van den Bent, M., Weller, M., Fisher, B., Taphoorn, M., et al. (2005). Radiotherapy plus concomitant and adjuvant temozolomide for globlastoma. N. Engl. J. Med. 352, 987-996. doi: 10.1016/j.canrad.2005.05.001

Takeuchi, H., Jin, S., Wang, J., Zhang, G., Kawanokuchi, J., Kuno, R., et al. (2006). Tumor Necrosis factor- $\alpha$ induces neurotoxicity via glutamate release from hemichannels of activated microglia in an autocrine manner. J. Biol. Chem. 281, 21362-21368. doi: 10.1074/jbc.M600504200

Tsuchida, S., Arai, Y., Kishida, T., Takahashi, K. A., Honjo, K., Terauchi, R., et al. (2013). Silencing the expression of connexin 43 decreases inflammation and joint destruction in experimental arthritis. J. Orthop. Res. doi: 10.1002/jor.22263

Tsuda, M., Kohro, Y., Yano, T., Tsujikawa, T., Kitano, J., Tozaki-Saitoh, H., et al. (2011). JAK-STAT3 pathway regulates spinal astrocyte proliferation and neuropathic pain maintenance in rats. Brain 134, 1127-1139. doi: 10.1093/ brain/awr025

Verkhratsky, A., Olabarria, M., Noristani, H. N., Yeh, C.-Y., and Rodriguez, J. J. (2010). Astrocytes in Alzheimer's disease. Neurotherapeutics 7, 399-412. doi: 10.1016/j.nurt.2010.05.017

Wang, H., Cao, Y., Chiang, C.-Y., Dostrovsky, J. O., and Sessle, B. J. (2014). The gap junction blocker carbenoxolone attenuates nociceptive behavior and medullary dorsal horn central sensitization induced by partial infraorbital nerve transection in rats. Pain 155, 429-435. doi: 10.1016/j.pain.2013.11.004

Wang, H., and Sun, X. (2017). Carbon monoxide-releasing molecule-2 inhibits connexin 43-hemichannel activity in spinal cord astrocytes to attenuate neuropathic pain. J. Mol. Neurosci. 63, 58-69. doi: 10.1007/s12031-017-0957-2

Wang, L., Peng, Y., Peng, J., Shao, M., Ma, L., Zhu, Z., et al. (2018). Tramadol attenuates the sensitivity of glioblastoma to temozolomide through the suppression of $\mathrm{Cx} 43$-mediated gap junction intercellular communication. Int. J. Oncol. 52, 295-304. doi: 10.3892/ijo.2017.4188

Wang, N., De Vuyst, E., Ponsaerts, R., Boengler, K., Palacios-Prado, N., Wauman, J., et al. (2013). Selective inhibition of Cx43 hemichannels by Gap19 and its impact on myocardial ischemia/reperfusion injury. Basic Res. Cardiol. 108:309. doi: 10.1007/s00395-012-0309-X

Wang, Y., Wu, Z., Liu, X., and Fu, Q. (2013). Lamina gastrodin ameliorates Parkinson's disease by downregulating connexin 43. Mol. Med. Rep. 8, 585-590. doi: 10.3892/mmr.2013.1535

Weyerbacher, A. R., Xu, Q., Tamasdan, C., Shin, S. J., and Inturrisi, C. E. (2010). N-Methyl-D-aspartate receptor (NMDAR) independent maintenance of inflammatory pain. Pain 148, 237-246. doi: 10.1016/j.pain.2009. 11.003

Wu, X. F., Liu, W. T., Liu, Y. P., Huang, Z. J., Zhang, Y. K., and Song, X. J. (2011). Reopening of ATP-sensitive potassium channels reduces neuropathic pain and regulates astroglial gap junctions in the rat spinal cord. Pain 152, 2605-2615. doi: 10.1016/j.pain.2011.08.003

Xu, H., Gu, S., Riquelme, M. A., Burra, S., Callaway, D., Cheng, H., et al. (2015). Connexin 43 channels are essential for normal bone structure and osteocyte viability. J. Bone Miner. Res. 30, 436-448. doi: 10.1002/jbmr.2374

Xu, Q., Cheong, Y.-K., He, S.-Q., Tiwari, V., Liu, J., Wang, Y., et al. (2014). Suppression of spinal connexin 43 expression attenuates mechanical hypersensitivity in rats after an L5 spinal nerve injury. Neurosci. Lett. 566, 194-199. doi: 10.1016/j.neulet.2014.03.004

Yang, C., Rahimpour, S., Yu, A. C. H., Lonser, R. R., and Zhuang, Z. (2013). Regulation and dysregulation of astrocyte activation and implications in tumor formation. Cell. Mol. Life Sci. 70, 4201-4211. doi: 10.1007/s00018-013-1274-8

Yang, H., Yan, H., Li, X., Liu, J., Cao, S., Huang, B., et al. (2018). Inhibition of connexin 43 and phosphorylated NR2B in spinal astrocytes attenuates bone cancer pain in mice. Front. Cell. Neurosci. 12:129. doi: 10.3389/fncel.2018. 00129

Yi, C., Ezan, P., Fernández, P., Schmitt, J., Sáez, J. C., Giaume, C., et al. (2017a). Inhibition of glial hemichannels by boldine treatment reduces neuronal suffering in a murine model of Alzheimer's disease. Glia 65, 1607-1625. doi: 10.1002/glia.23182

Yi, C., Koulakoff, A., and Giaume, C. (2017b). Astroglial connexins as a therapeutic target for Alzheimer's disease. Curr. Pharm. Des. 23, 4985-4968. doi: 10.2174/ 1381612823666171004151215

Yi, C., Mei, X., Ezan, P., Mato, S., Matias, I., Giaume, C., et al. (2016). Astroglial connexin43 contributes to neuronal suffering in a mouse model of Alzheimer's disease. Cell Death Differ. 23, 1691-1701. doi: 10.1038/cdd. 2016.63

Zhang, F. F., Morioka, N., Kitamura, T., Fujii, S., Miyauchi, K., Nakamura, Y., et al. (2016). Lycopene ameliorates neuropathic pain by upregulating spinal astrocytic connexin 43 expression. Life Sci. 155, 116-122. doi: 10.1016/j.lfs.2016. 05.021

Conflict of Interest Statement: The authors declare that the research was conducted in the absence of any commercial or financial relationships that could be construed as a potential conflict of interest.

Copyright (C) 2019 Xing, Yang, Cui and Chen. This is an open-access article distributed under the terms of the Creative Commons Attribution License (CC BY). The use, distribution or reproduction in other forums is permitted, provided the original author(s) and the copyright owner(s) are credited and that the original publication in this journal is cited, in accordance with accepted academic practice. No use, distribution or reproduction is permitted which does not comply with these terms. 